\title{
Limitation of the environmental impact of ashes from combustion of sewage sludge by the synthesis of zeolites
}

\author{
Jolanta Latosińska ${ }^{1, *}$ \\ ${ }^{1}$ Kielce University of Technology, Faculty of Environmental, Geomatic and Energy Engineering, Al. \\ Tysiąclecia Państwa Polskiego 7, 25-324 Kielce, Poland
}

\begin{abstract}
The combustion of municipal sewage sludge allows for the recovery of renewable energy. However, it simultaneously causes the formation of ash which is not neutral for the environment. The study presents the research on the possibility of using sewage sludge ash as a raw material for the synthesis of zeolites. The synthesis of zeolites was performed with the use of an indirect fusion method and a direct hydrothermal method. The research on sewage sludge ash after zeolitization included the identification of crystalized phases, the observation of changes of ash particles surface and the measurement of cation exchange capacity (CEC). The research results proved that optimal conditions for the formation of zeolite $\mathrm{Y}$ were the synthesis with the indirect fusion method at the sewage sludge ash to hydroxy sodalite ratio of $1: 1.8$, the activation temperature of $60^{\circ} \mathrm{C}$ and the crystallization temperature of $90^{\circ} \mathrm{C}$. Hydroxy sodalite was found in samples from both methods of zeolitization. However, in the case of direct hydrothermal method, particles of hydroxy sodalite structure were less numerous indicating a small conversion of sewage sludge ash to crystalline zeolite. CEC values comparable to commercial zeolites resulted from zeolitization with the indirect fusion method.
\end{abstract}

\section{Introduction}

Municipal sewage sludge, an unavoidable by-product of wastewater treatment plants, is classified as biomass [1]. Sewage sludge contains $40-85 \%$ of organic matter which is the source of renewable energy [2]. The recovery of energy from sewage sludge may be realized by mono-combustion and co-combustion. However, the combustion of sewage sludge causes the formation of sewage sludge ash, whose weight equals approximately $10 \%$ of the weight of incinerated sewage sludge [3]. There are known methods of using sewage sludge ash in the production of building materials [4-5], the stabilization of soils [6] and the recovery of phosphorus [7]. However, the dominant method of sewage sludge ash disposal is a landfilling [8]. The landfilling of sewage sludge ash poses a threat to the natural environment [9].

\footnotetext{
${ }^{*}$ Corresponding author: jlatosin@tu.kielce.pl
} 
Zeolites are tectosilicates with a framework of $\left[\mathrm{AlO}_{4}\right]^{-5}$ and $\left[\mathrm{SiO}_{4}\right]^{-4}$ tetrahedra, connected with one common oxygen atom. The connection of tetrahedra generates the existence of empty spaces in the structure [10]. Due to such properties as high ion exchange, high thermal, mechanical and chemical stability, zeolites are commonly used as ion exchangers, molecular sieves, catalysts and adsorbents [11-12]. Synthetic zeolites can be produced from natural raw materials such as kaolinite [13], montmorillonite [14]. Waste materials are also used for the synthesis of zeolites as the carriers of $\mathrm{SiO}_{2}$ and $\mathrm{Al}_{2} \mathrm{O}_{3}$. Zeolites are obtained among others from coal fly ash [15], rice husk ash [16], municipal incinerator fly ash [17].

A significant similarity of the oxide composition of sewage sludge ash to the composition of coal fly ash used for the synthesis of zeolites is the basis for the beginning of research in this aspect (tab.1.).

Table 1. Chemical composition of ashes.

\begin{tabular}{|c|c|c|c|}
\hline \multirow{2}{*}{ Component } & Sewage sludge ash & \multicolumn{2}{|c|}{ Coal fly ash } \\
\cline { 3 - 4 } & {$[\mathbf{1 8}]$} & {$[\mathbf{1 9 ]}$} & {$[\mathbf{2 0 ]}$} \\
\hline $\mathrm{SiO}_{2}$ & 35.7 & 34.4 & 38.5 \\
\hline $\mathrm{Al}_{2} \mathrm{O}_{3}$ & 6.7 & 17.9 & 15.9 \\
\hline $\mathrm{Fe}_{2} \mathrm{O}_{3}$ & 9.6 & 10.4 & 9.6 \\
\hline $\mathrm{CaO}$ & 17.5 & 20.4 & 14.2 \\
\hline $\mathrm{MgO}$ & 4.51 & 1.5 & 1.8 \\
\hline $\mathrm{SO}_{3}$ & 1.2 & n.d. & n.d. \\
\hline $\mathrm{K}_{2} \mathrm{O}$ & 1.6 & 0.8 & 1.6 \\
\hline $\mathrm{Na}_{2} \mathrm{O}$ & 0.5 & 1.5 & 0.9 \\
\hline $\mathrm{P}_{2} \mathrm{O}_{5}$ & 19.0 & n.d. & n.d. \\
\hline $\mathrm{TiO}_{2}$ & 1.0 & 1.0 & n.d. \\
\hline
\end{tabular}

The synthesis of zeolites from ashes can be realized with one of the methods: a direct hydrothermal method [21], an indirect fusion followed by a hydrothermal method [22-23], a two step hydrothermal method [24] and a molten salt liquid free method [25]. The most commonly used methods are the hydrothermal and fusion methods [26-27]. The ratio of silicone to aluminum used for the synthesis of the raw material influences the type of obtained zeolite. Moreover, factors such as the concentration and type of alkaline, temperature, pressure and reaction time determine the obtainment of different zeolites from the same fly ash [28].

The aim of the study is the evaluation of the possibility of using sewage sludge ash for the synthesis of zeolites and the evaluation of the impact of the zeolitization method on the ion-exchange properties of obtained products. It is a pioneering study on zeolitization of municipal sewage sludge ash by the indirect fusion method.

\section{Materials and methods}

\subsection{Materials}

In this study sewage sludge from a municipal wastewater treatment plant in SitkówkaNowiny near Kielce was used. The wastewater treatment plant receives sewage from Kielce agglomeration, located in the central part of Poland.

Sewage sludge ash was obtained as a result of sewage sludge incineration in a laboratory furnace. Sewage sludge was dried in a laboratory drier at $105^{\circ} \mathrm{C}$. Then, it was 
crushed in a mortar to a fraction $<125 \mu \mathrm{m}$. Sewage sludge was incinerated in a laboratory furnace at the temperature of $600^{\circ} \mathrm{C}$ within 11 minutes. The time of sample incineration included the period of furnace warm-up, combustion at a given maximal temperature and the furnace cooling down to the temperature of $20^{\circ} \mathrm{C}$.

\subsection{Methods of zeolite synthesis}

The synthesis of zeolite materials was investigated with two methods: the indirect fusion and the direct hydrothermal method. Different ratios of sewage sludge ash to $\mathrm{NaOH}$ samples were used to explore the effect of this parameter on zeolitization. The synthesis conditions for each sample are shown in Table 2.

Table 2. Experimental conditions of sewage sludge ash zeolitization.

\begin{tabular}{|c|c|c|c|c|}
\hline \multirow{2}{*}{ Sample } & \multirow{2}{*}{$\begin{array}{c}\text { SSA:NaOH } \\
\text { g/g }\end{array}$} & \multirow{2}{*}{$\begin{array}{c}\text { Activation } \\
\text { temperature, }{ }^{\circ} \mathrm{C}\end{array}$} & \multicolumn{2}{|c|}{ Crystallization temperature, ${ }^{\circ} \mathrm{C}$} \\
\hline & & & Indirect fusion & Direct hydrothermal \\
\hline S1 & $1: 1.4$ & 60 & 60 & - \\
\hline S2 & $1: 1.4$ & 60 & 90 & - \\
\hline S3 & $1: 1.4$ & 90 & 60 & - \\
\hline S4 & $1: 1.4$ & 90 & 90 & - \\
\hline S5 & $1: 1.4$ & 60 & - & 60 \\
\hline S6 & $1: 1.4$ & 60 & - & 90 \\
\hline S7 & $1: 1.4$ & 90 & - & 60 \\
\hline S8 & $1: 1.4$ & 90 & - & 90 \\
\hline S9 & $1: 1.8$ & 60 & 60 & - \\
\hline $\mathrm{S} 10$ & $1: 1.8$ & 60 & 90 & - \\
\hline S11 & $1: 1.8$ & 90 & 60 & - \\
\hline $\mathrm{S} 12$ & $1: 1.8$ & 90 & 90 & - \\
\hline $\mathrm{S} 13$ & $1: 1.8$ & 60 & - & 60 \\
\hline S14 & $1: 1.8$ & 60 & - & 90 \\
\hline $\mathrm{S} 15$ & $1: 1.8$ & 90 & - & 60 \\
\hline S16 & $1: 1.8$ & 90 & - & 90 \\
\hline
\end{tabular}

\subsubsection{Indirect fusion followed by a hydrothermal method}

Sewage sludge ash particles in the amount of $10 \mathrm{~g}$ were mixed and ground with granular $\mathrm{NaOH}$ to obtain a homogeneous mixture. The mixture was heated in an electric laboratory furnace at the temperature of $550^{\circ} \mathrm{C}$ for 1 hour. The sintered mixture was ground and mixed with distilled water (the applied concentration 3 molar $\mathrm{NaOH}$ ), followed by an aging process with an agitation in a shaking water bath at given temperatures within 12 hours. Then the mixture was crystallized under static conditions at the given temperature within 6 hours. After the completion of the crystallization, the solid product was washed several times with distilled water until the $\mathrm{pH}$ of the solution reached 10.0 , then dried at $105^{\circ} \mathrm{C}$ for 10 hours. 


\subsubsection{Direct hydrothermal method}

Sewage sludge ash particles in the amount of $10 \mathrm{~g}$ were mixed with a 3 molar $\mathrm{NaOH}$ solution. Then the samples were subjected to activation and crystallization under respectively the same process conditions as for the indirect fusion method followed by a hydrothermal method.

\subsection{Characterization methods}

The chemical compositions of sewage sludge and sewage sludge ash were determined by using the X-ray fluorescence spectroscopy (XRF) method. The research on sewage sludge ash before and after the process of zeolitization included a phase analysis by the X-ray diffraction (XRD). The identification of phases was performed by the comparison of recorded diffractograms and the benchmarks in base ICDD PD-2 and PDF-4+2014.

The evaluation of grain structure change was observed with the scanning electron microscopy (SEM).

The cation exchange capacity (CEC) was determined with the use of ammonium acetate. CEC is a measurement of the number of cations in the channels by unit weight that may be replaced by other ions in solutions. The exchangeable cations of samples were replaced by $\mathrm{NH}_{4}{ }^{+}$using $1 \mathrm{M}$ ammonium acetate [29]. The concentration of ammonium ions in solutions was determined with the use of ion chromatography.

\section{Results and discussion}

The characteristics of sewage sludge and sewage sludge ash are presented in Table 3 . A significant increase of the content of certain elements in sewage sludge ash in comparison to their content in sewage sludge is caused by among others different volatility of compounds. The volatility of organic compounds is higher in comparison to the volatility of inorganic compounds. Sewage sludge ash is a high-silica ash because the ratio of $\mathrm{SiO}_{2}$ and $\mathrm{Al}_{2} \mathrm{O}_{3}$ equals 3.94 .

Table 3. Characteristics of sewage sludge and sewage sludge ash.

\begin{tabular}{|c|c|c|c|}
\hline Parameter & Unit & Sewage sludge & Sewage sludge ash \\
\hline $\mathrm{pH}$ & - & 7.5 & - \\
\hline moisture & $\%$ & 72.6 & - \\
\hline $\mathrm{SiO}_{2}$ & $\%$ & 8.81 & 20.8 \\
\hline $\mathrm{Al}_{2} \mathrm{O}_{3}$ & $\%$ & 2.11 & 5.28 \\
\hline $\mathrm{Fe}_{2} \mathrm{O}_{3}$ & $\%$ & 3.74 & 9.45 \\
\hline $\mathrm{CaO}$ & $\%$ & 5.66 & 14.3 \\
\hline $\mathrm{MgO}$ & $\%$ & 1.42 & 3.72 \\
\hline $\mathrm{SO}$ & $\%$ & 0.01 & 1.45 \\
\hline $\mathrm{K}_{2} \mathrm{O}$ & $\%$ & 0.58 & 1.51 \\
\hline $\mathrm{Na}_{2} \mathrm{O}$ & $\%$ & 0.16 & 0.41 \\
\hline $\mathrm{P}_{2} \mathrm{O}_{5}$ & $\%$ & 7.06 & 19.4 \\
\hline $\mathrm{TiO}_{2}$ & $\%$ & 0.32 & 0.73 \\
\hline $\mathrm{Mn}_{2} \mathrm{O}_{3}$ & $\%$ & 0.03 & 0.10 \\
\hline
\end{tabular}




\begin{tabular}{|c|c|c|c|}
\hline $\mathrm{SrO}$ & $\%$ & 0.02 & 1.45 \\
\hline $\mathrm{ZnO}$ & $\%$ & 0.03 & 0.36 \\
\hline $\mathrm{BaO}$ & $\%$ & 0.04 & 0.09 \\
\hline $\mathrm{CuO}$ & $\%$ & 0.02 & 0.05 \\
\hline $\mathrm{TOC}$ & $\%$ mas. & 33.69 & - \\
\hline
\end{tabular}

Sewage sludge ash consists of: amorphous substance $-76.71 \%$ mas., quartz $-9.12 \%$ mas., calcite $4.06 \%$ mas., dolomite $-3.28 \%$ mas., muscovite $-4.42 \%$ mas., potassium feldspar $-1.72 \%$ mas., plagioclase $-0.47 \%$ mas. and other $-0.22 \%$ mas.

The XRD diffractograms were presented in figure 1 - figure 2. Diffractograms of samples S1, S2, S3, S4 and S9 indicate that zeolites were not formed while obtained phases were apatite, quartz and magnetite. Therefore for given activation and crystallization temperatures, no differences were found in formed crystalline phases for samples with the SSA: $\mathrm{NaOH}$ ratio of 1:1.4. Whereas, a noticeable lack of zeolite structure in sample S5 was caused by an insufficient value of the activation and crystallization temperatures.

Zeolite Y (faujasite) is presented by the diffractogram of sample S10. Depending on the silicone to aluminum ratio of the raw material, faujasite is divided into $\mathrm{X}$ and $\mathrm{Y}$. Zeolite $\mathrm{X}$ is obtained as a result of the synthesis of raw materials with the ratio between 2 and 3 [29], while zeolite $\mathrm{Y}$ with the ratio from 3 and more [31]. Zeolite $\mathrm{Y}$, obtained under the conditions of zeolitization of sample S10, proves that the synthesis at the crystallization temperature of $90^{\circ} \mathrm{C}$ is more favorable than at $60^{\circ} \mathrm{C}[32]$.

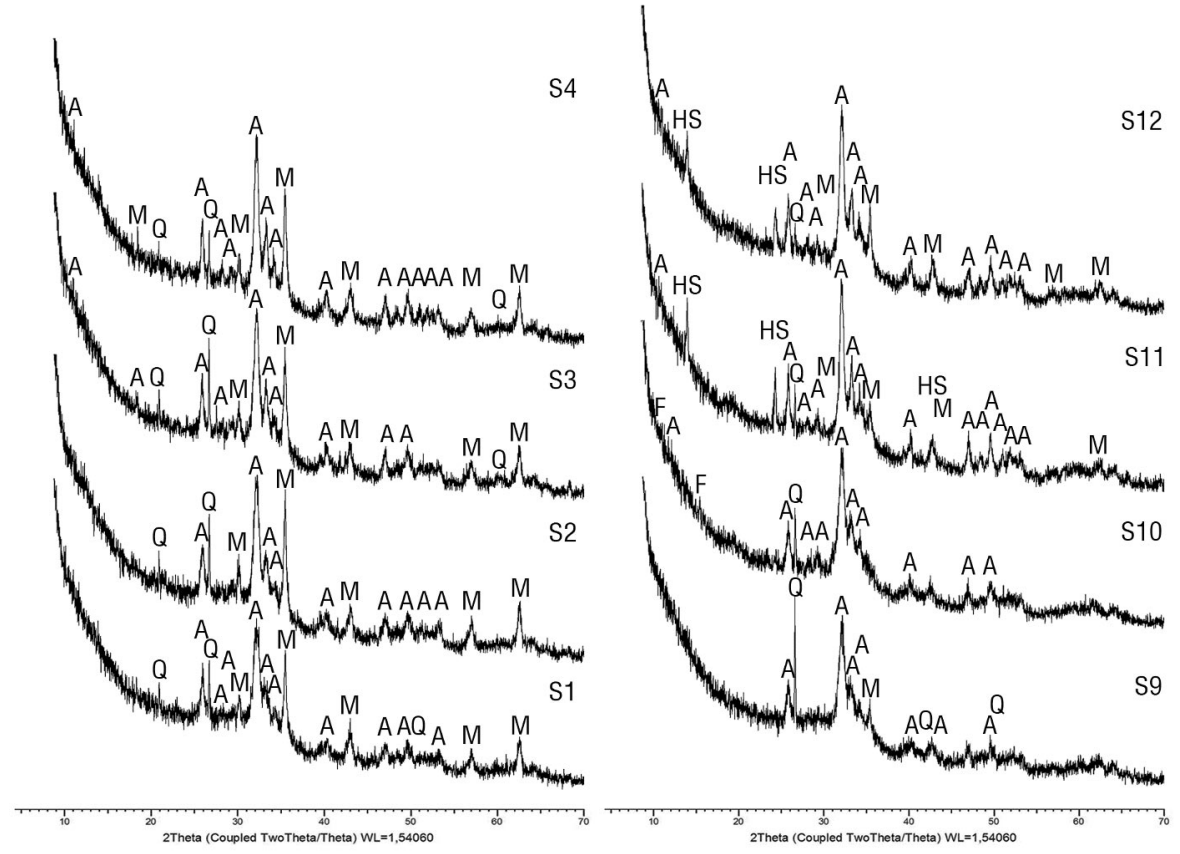

Fig. 1. XRD of the synthetic zeolites by indirect fusion method: A-apatite; F- faujasite; M- magnetite, HS-hydroxy sodalite; Q-quartz.

Diffractograms of samples S11 and S12 show that except for apatite, quartz and magnetite, hydroxy sodalite was also formed. Hydroxy sodalite has the same framework structure as sodalite. Its structure is made up of a framework of 4 - and 6- membered rings 
of $\mathrm{SiO}_{4}$ and $\mathrm{AlO}_{4}$ tetrahedra [33]. The pore size of hydroxy sodalite is smaller than of the zeolites with an eight-member ring aperture [34]. This feature provides many advantages, particularly the access to small molecules like ammonia and water. Therefore hydroxy sodalite is an attractive material for wide applications, such as hydrogen separation, catalysts and pigment occlusion [35-36].

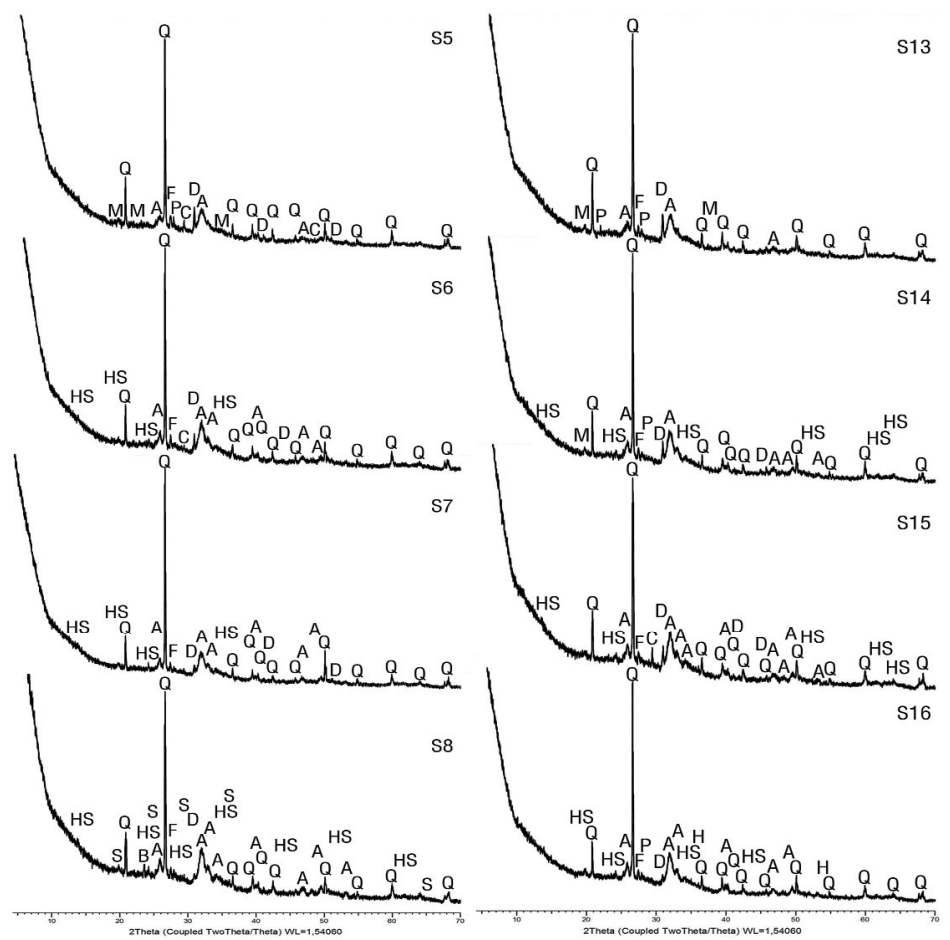

Fig.2. XRD of the synthetic zeolites by direct hydrothermal method; Q- quartz, F- potassium feldspar, A-apatite, HS-hydroxy sodalite, M- muscovite, D- dolomite, P- plagioclase, C-calcite.

Samples S5-S8 and S13-S16 obtained as a result of zeolitization with the direct hydrothermal method are characterized by a greater diversity of identified phases in comparison to samples from the indirect fusion method. All samples S5-S8 and S13-S16 except for quartz and apatite contained dolomite and potassium feldspar. The presence of dolomite and potassium feldspar in sewage sludge ash and subsequently in samples after zeolitization with the direct hydrothermal method indicates that both mentioned phases were not entirely transformed. Sample S5, except for the above mentioned phases, contained also plagioclase, calcite and muscovite which were present in sewage sludge ash. The lack of new phases in sample S5 and S13 proves that the activation and crystallization temperatures had insufficient values for the occurrence of effective zeolitization.

Diffractograms of samples S6-S8 and S14-S16 present a zeolite - hydroxy sodalite. The intensity of hydroxy sodalite peaks for these samples is smaller than for samples S11 and $\mathrm{S} 12$. For samples S5-S8 and S13-S16 the influence of the SSA:NaOH ratio on the formation of new phases was not found. Whereas, the greatest change in the quality of phases in comparison with the sewage sludge ash used was stated only for samples S7 and S8. Calcite, muscovite and plagioclase were not found in samples S7 and S8. Therefore, the activation temperature of $90^{\circ} \mathrm{C}$ is required in order to conduct the process of zeolitization. According to [37], zeolitization of sewage sludge ash with the hydrothermal method for among many a 3 molar concentration of $\mathrm{NaOH}$, the crystallization temperature of $100^{\circ} \mathrm{C}$ 
and the crystallization time of 10 hours also did not cause the formation of clear zeolites, i.e. Zeolite P and hydroxy sodalite. Other crystalline forms present in sewage sludge ash were also in samples after the process of zeolitization.

Figure 3 shows the SEM micrograph of the original sewage sludge ash. The SEM presents particles with a compact structure and a smooth surface because of the amorphous substance covering them.

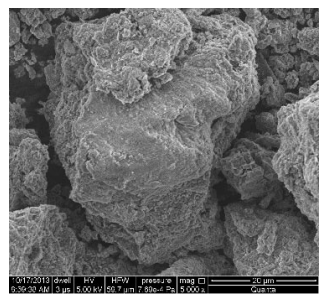

Fig. 3.SEM of sewage sludge ash.
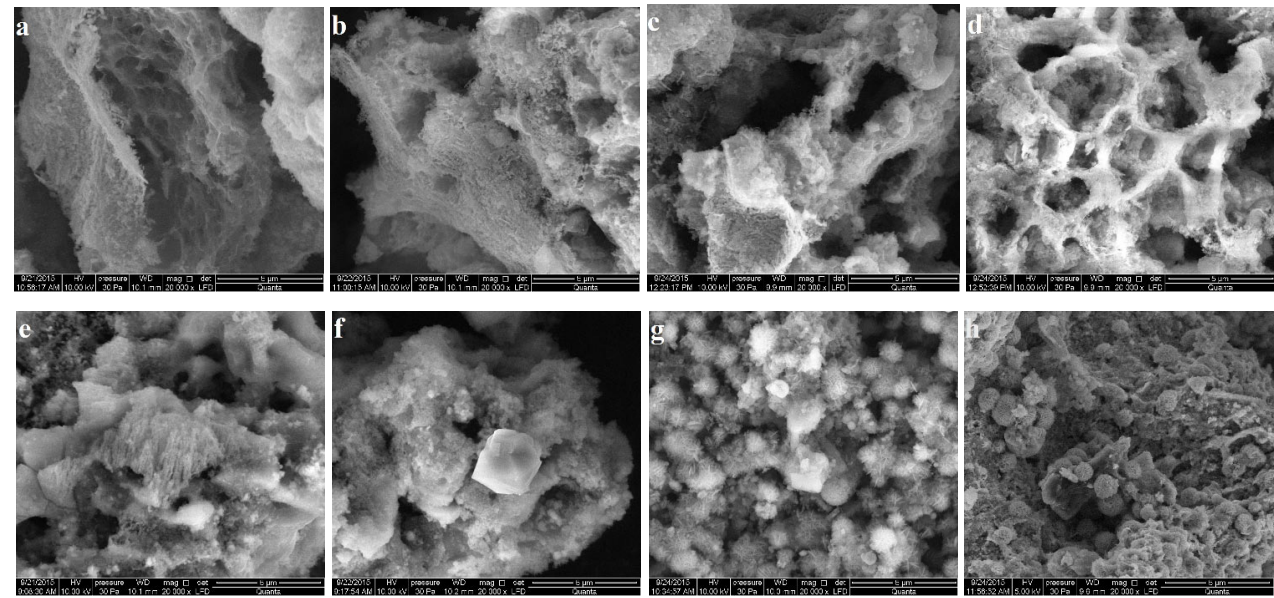

Fig. 4. SEM of the synthetic zeolites by indirect fusion method; (a) S1; (b) S2; (c) S3; (d) S4; (e) S9; (f) $\mathrm{S} 10 ;$ (g) S11; (h) S12.
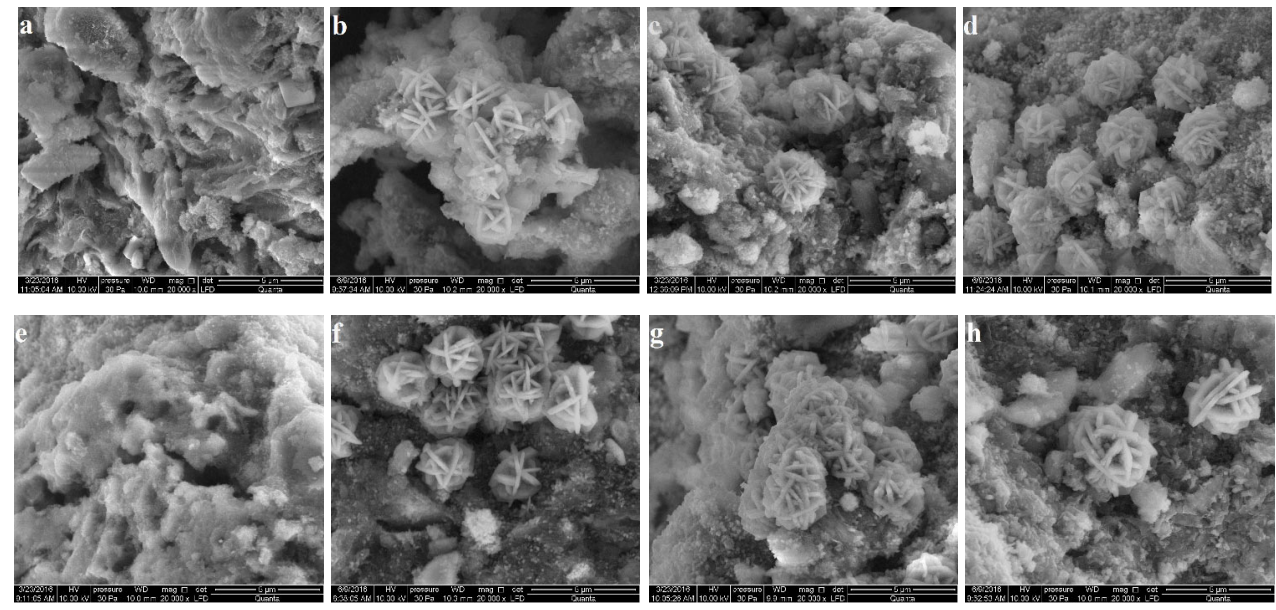

Fig. 5. SEM of the synthetic zeolites by direct hydrothermal method; (a) S5; (b) S6; (c) S7; (d) S8; (e) S13; (f) S14; (g) S15; (h) S16. 
Figure 4 shows images of samples after zeolitization by the indirect fusion method. The morphology of samples S1, S2, S3 and S4, obtained at the lowest SSA:NaOH ratio has porous surface (fig.4.a-fig.4.d). The structure of sample S9-S12, obtained at the ratio $\mathrm{SSA}: \mathrm{NaOH} 1: 1.8$ (fig.4.e-fig.4.h) is also not homogeneous. Apart from the porous structure, there are also forms with the shape similar to long needles with uneven surface (fig.4.e). The morphology of SEM image for zeolite $\mathrm{Y}$ is an octahedral shape (fig.4.f). As illustrated in figures $4 . \mathrm{g}-4$.h, the hydroxy sodalite has a particle size smaller than $5 \mu \mathrm{m}$.

Figure 5 presents SEM of samples after the process of zeolitization with the direct hydrothermal method. Samples S5 and S13 (fig.5.a, fig.5.e) are characterized by a solid structure, a lack of zeolites and clearly noticeable amorphous substance. For samples S6-S8 and S14-S16 the presence of not numerous particles of hydroxy sodalite structure on the amorphous substance indicates a small conversion of sewage sludge ash to crystalline zeolite.

SEM images of the samples formed in this study reveal the change in morphology connected with the zeolitization method.

SEM images confirm the results of the phase analysis. Peaks of high intensity in a low angle range characteristic for zeolite phases do not appear for samples S6-S7 and S14-S16. The peaks are small, often with the intensity similar to the background.

The CEC results of sewage sludge ashes and ashes after zeolitization are presented in figure 6. The CEC values of sewage sludge ashes subjected to zeolitization with the indirect fusion method are higher in comparison to the values of raw sewage sludge ash. There is a relation for this method of zeolitization, i.e. higher CEC values of samples with the SSA: $\mathrm{NaOH}$ ratio of 1:1.4 in comparison to samples with the SSA: NaOH ratio of 1:1.8. Whereas, there is no significant influence of the activation and crystallization temperatures on CEC values in the case of all tested samples for both methods of zeolitization.

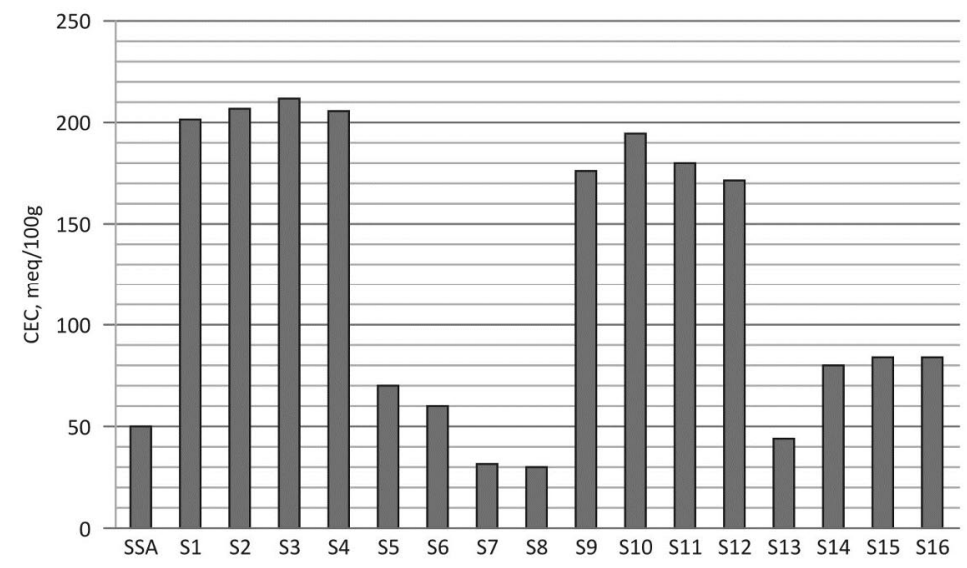

Fig. 6. CEC of sewage sludge ash (SSA) and samples after zeolitization.

The CEC values for samples S7, S8 and S13 obtained as a result of zeolitization with the direct hydrothermal method are lower than those of raw sewage sludge ash. Whereas, the CEC values for samples S5, S6, S14-S16 are higher than the values of raw sewage sludge ash but they do not reach the levels of the CEC values of samples subjected to the synthesis with the indirect fusion method. Sample S3 has the highest CEC value from all the tested samples. The CEC value is $426 \%$ higher than the value for the raw sewage sludge ash. Whereas, the lowest CEC value belongs to sample S8, obtained as a result of zeolitization with the direct hydrothermal method for the SSA:NaOH ratio of 1:1.4. The CEC value is more than $39 \%$ lower than the value for the raw sewage sludge ash. 
All samples obtained as a result of the synthesis with the fusion method have significantly higher CEC values in comparison to $\mathrm{CEC}$ values of the remaining samples. For samples S1-S4 and S9, the increase of the CEC values is not simultaneous with the formation of zeolite phases. SEM images show that samples S1-S4 and S9-S12 have a more developed porous structure than samples obtained as a result of zeolitization with a direct hydrothermal method. Therefore, it is possible that higher CEC values are not necessarily the evidence of the ion exchange but the occurrence of a different process, for instance the sorption on the porous surface.

Sewage sludge ash subjected to zeolitization with the indirect fusion method has the CEC values at a similar level as the CEC values of natural zeolites. The CEC values of natural zeolites are in the range of 200-500 meq/100g [38-39]. There are zeolites of higher CEC values, for instance pure hydroxy sodalite has a CEC value of $920 \mathrm{meq} / 100 \mathrm{~g}$ [40]. CEC values of the tested samples, significantly lower than CEC values of pure hydroxyl sodalite are approximately the evidence of a small degree of conversion of tested sewage sludge ash into a zeolite material. It is the approximation because other processes may occur apart from the ion exchange. Moreover, the comparison of the obtained CEC values with the literature data involves a little authoritativeness due to the diversity of methods of conducting the ion exchange process.

\section{Conclusions}

The study presents the test results of the synthesis of zeolites from sewage sludge ash with the indirect fusion method and the direct hydrothermal method. The results show that synthesis products of better properties can be obtained with the use of the indirect fusion method rather than the direct hydrothermal method.

From a practical point of view, the optimal conditions for the synthesis of zeolite $\mathrm{Y}$ are provided by the indirect fusion method at the sewage sludge ash to sodium hydroxide ratio of $1: 1.8$, the activation temperature of $60^{\circ} \mathrm{C}$ and the crystallization temperature of $90^{\circ} \mathrm{C}$.

The indirect fusion method should also be used in order to obtain hydroxy sodalite from sewage sludge ash. Moreover, zeolitization with the indirect fusion method caused an increase of the cation exchange capacity value of sewage sludge ash to the level of commercial zeolites.

The combustion of municipal sewage sludge, apart from the energy recovery, allows to obtain a material which can be used as a raw material for the synthesis of zeolites. The obtained zeolites can be used for the removal of ammonium ions from sewage.

The project was funded by the National Science Centre allocated on the basis of the decision DEC2011/03/D/ST8/04984, in Poland.

\section{References}

1. Directive 2012/27/EU of the European Parliament and of the Council of 25 October (2012)

2. M. De la Guardia, A. Morales-Rubio, Trends Anal. Chem. 8, 311-318 (1996)

3. J. Werther, T. Ogada, Prog. Energy Combust. Sci.25, 1-27 (1999)

4. D.-F. Lin, C.-H. Weng, J. Environ. Engineering 6, 922-927 (2001)

5. J. Monzó, J. Payá, M.V. Borrachero, I. Girbés, Waste Manage. 23, 373-381 (2003)

6. L. Chen, D-F. Lin, J. Hazard. Mater. 162, 338-343 (2009)

7. C. Adam, G. Kley, F.G. Simon, Mater. Trans. 48, 3056-3061(2007)

8. Eurostat http://appsso.eurostat.ec.europa.eu 
9. J. Latosińska, J. Gawdzik, EPE Journal, 38, 31-44 (2012)

10. M. Król, J. Morawska, W. Mozgawa, W. Pichór, Ceram. Mater. 66, 129-134 (2014)

11. L. Bandura, R. Panek, M. Rotko, W. Franus, Microporous and Mesoporous Mater. 223, 1-9 (2016)

12. W. Qiu, Y. Zheng, Chem. Eng. J. 145, 483-488 (2009)

13. M. Murat, A. Amokrane, J.P. Bastide, L. Montanaro, Clay Miner.27, 119-130 (1992)

14. P. Cañizares, A. Durán, F. Dorado, M. Carmona, Appl. Clay. Sci. 16, 273-287 (2000)

15. X. Querol, N. Moreno, J.C. Umaña, A. Alastuey, E. Hernández, A. López-Soler, F. Plana, Int. J. Coal Geol. 50, 413 - 423 (2002)

16. D. Prasetyoko, Z. Ramli, S. Endud, H. Hamdan, B. Sulikowski, Waste Manag. 26, 1173-1179 (2006)

17. G. C. C. Yang, T. Y. Yang, J. Hazard. Mater. 62, 75-89 (1998)

18. J. Latosińska, J. Gawdzik, Ecol. Chem. Eng. S. 21, 465-475 (2014)

19. D. Wu, Z. Hu, X. Wang, S. He, H. Kong, Front. Environ. Sci. Engin. China. 1, $223-$ 220 (2007)

20. K.-M.Lee, Y.-M. Jo, J Mater Cycles Waste Manag. 12, 212-219 (2010)

21. X. Querol, A. Alastuey, J.L. Fernandez-Turiel, A. Lopez-Soler, Fuel. 74, 1126-1231 (1995)

22. N. Shigemoto, H. Hayashi, K. Miyara. J Material Science. 28, 4781-4786 (1993)

23. N. Czuma, K. Zarębska, P. Baran, Analysis of the influence of fusion synthesis parameters on the SO2 sorption properties of zeolites produced out of fly ash, E3S Web of Conferences 10, 00010 (2016)

24. H. Tanaka, S. Furusawa, R. Hino, J Material Synthetic Processing. 10, 143-148 (2002)

25. M. Park, C.L. Choi, W.T. Lim, M.C. Kim, J. Choi, N.H. Heo, Microporous and Mesoporous Mater. 37, 81-89 (2000)

26. A. Molina, C. Poole, Minerals Engineering. 17, 167-173 (2004)

27. C.A. Ríos, C.D. Williams, O.M. Castellanos, Bistua. 4, 60-71 (2006)

28. A. Derkowski, W. Franus, E. Beran, A. Czimerova, Power Technology. 166,47-54 (2006)

29. N. Czuma, K. Zarębska, P. Baran, W. Franus, The process of fly ash magnetic separation impact on hydrothermal synthesis of zeolites, E3S Web of Conferences 10, 00009, (2016)

30. H. Minato, Standarizaton of Methods for Zeolite Speciality Determination and techniques for Zeolite resources utilization, Natural Zeolites - SOFIA'95 282-292 (1995)

31. D.N. Stamires, Clays Clay Miner. 21, 379-389 (1973)

32. K. Fukui, T. Nishimoto, M. Takiguchi, H. Yoshida, KONA Power and Particle Journal. 24, 183-190 (2006)

33. T. Wajima, K. Munakata, Y Ikegami, Mater. Trans. 51, 849-854 (2010)

34. B. Bayati, A.A. Babaluo, P. A. Namini, Iran J. Chem. Chem. Eng. 28, 1-12 (2009)

35. J.C. Kim, M. Choi, D-S. Kim, H.J. Song, D-W. Kim, J. Ceram. Soc. Jpn. 123, 1022$1026(2015)$

36. M.K. Naskar, D. Kumdu, M. Chatterjee, Mater. Lett. 65, 436-438 (2011)

37. J.S. Lee, S.W. Eom, H.Y. Choi, Kor. J. Env. Hlth. 33, 317-324 (2007)

38. K. Margeta, N. Z. Logar, M. Šiljeg, A. Farkas, Natural Zeolites in Water TreatmentHow Effective is Their Use, Water Treatment, W. Elshorbagy (Ed.), InTech, 81-112 (2013)

39. F.A. Mumpton, Mineralogy and Geology of Natural Zeolites, Mineralogical Soc. America (1981)

40. T. Henmi, Soil Sci. Plant Nutr. 33, 517-521 (1987) 